\title{
LEMBRAR PARA LEMBRAR E PARA ESQUECER: UM DIÁLOGO POSSÍVEL ENTRE DICKENS, FREUD E RICOEUR
}

\author{
REMEMBER TO REMEMBER AND TO FORGET: A POSSIBLE \\ DIALOGUE BETWEEN DICKENS, FREUD AND RICOEUR
}

\author{
Ernane Salles da Costa Junior
}

\section{RESUMO}

O artigo visar propor um diálogo entre a obra de Dickens e as reflexões de Ricoeur e Freud sobre as representações da temporalidade humana e suas implicações para se pensar o sentido performativo do projeto constituinte de 1988 como processo de aprendizado social. Toma-se como ponto de análise seus personagens literários para se examinar as patologias da memória contidas na relação obsessiva com o passado. A conclusão é de conceber o uso crítico da memória como espaço de experiência e de lição, de responsabilidade e autocorreção como abertura do projeto constituinte, aqui e agora, às vozes recalcadas do passado.

Palavras-chaves: Tempo. Memória. Constituição.

\section{ABSTRACT}

The article aims to propose a dialogue between the work of Dickens and the reflections of Ricoeur and Freud on the representations of human temporality and its implications to think the performative meaning of the 1988 constituent project as a process of social learning. It takes as its point of analysis its literary characters to examine the pathologies of memory 
contained in the obsessive relationship with the past. The conclusion is to conceive of the critical use of memory as a space of experience and lesson, of responsibility and self-correction as the opening of the constituent project, here and now, to the repressed voices of the past.

Keywords: Time. Memory. 1988 Constitution.

\section{INTRODUÇÃo}

0 presente artigo visa propor um diálogo entre a obra de Charles Dickens e as reflexões de Ricoeur e Freud sobre as representações do tempo humano, seus sentidos e implicações para se pensar o sentido performativo do projeto constituinte de 1988 como processo de aprendizado social.

Para tanto, busca-se, num primeiro momento, refletir sobre as patologias da temporalidade humana e o tempo da memória como tempo da reflexão, da consciência e do recomeço, a partir dos personagens: Scrooge, de "Conto de Natal", Pip, de "Grandes Esperanças" e Richard, de "Bleak House", criados por Dickens (2).

Em seguida, analisa-se especificamente a personagem Miss Harvisham, de "Grandes Esperanças" para se pensar a obsessão patológica com o passado, dor experimentada como repetição e onipresença, numa aproximação com o pensamento de Ricoeur e Freud (3).

Por fim, conclui-se que pensar a temporalidade humana como capacidade de reconstrução de sentidos pressupõe o uso crítico da memória política como espaço de experiência e de lição, como lugar de responsabilidade pelos erros e tropeços e capacidade de autocorreção como abertura do projeto constituinte, aqui e agora, às vozes recalcadas do passado (4).

\section{AS REPRESENTAÇÕES DO TEMPO NA OBRA DE DICKENS}

A temática do tempo e sua relação com a vida humana tem uma presença constante, seja de modo direto, seja de modo oblíquo, na obra de Charles Dickens. Alguns de seus livros, como “Great Expectations” (2013), 
"David Copperfield" (1972) e "Oliver Twist" (1966) abordam a infância por meio do resgate de uma memória em projeção: fragmentos do que se lembra vão sendo configurados em forma de narrativas em meio às descontinuidades das experiências vividas no tempo. Seus personagens literários experimentam a vida como narrativa contada, uma história permeada de conflitos e vicissitudes, de erros e tropeços, quase sempre à espera do tempo da redenção.

Esse tempo de redenção é tematizado na obra de Dickens a partir da importância atribuída à narrativa das experiências da vida como forma de construção da consciência de si e do outro num processo de transformação interna vivenciado por seus personagens. Em "Conto de Natal" (1988) essa dimensão temporal da consciência e da transformação de si se constitui em uma das marcas da trama. Ebenezer Scrooge, personagem central, é um velho aborrecido e avarento que passou a vida inteira acumulando sua fortuna e ignorando qualquer tipo de relações afetivas e contatos sociais. Na véspera do Natal, ele recebe a visita do espírito do seu ex-sócio Marley, morto há exatos sete anos. Marley conta que, mesmo morto, ainda sofre, pois seu espírito não pode ter paz em razão da vida que levara. 0 ex-sócio, então, avisa a Scrooge que esse ainda tem uma chance de mudar o rumo da sua história e que naquela mesma noite receberia a visita de três espíritos: o do Natal Passado, o do Natal presente e do Natal Futuro. Cada um seria ali responsável para ajudar Scrooge a percorrer as dimensões luminosas de suas vivências esquecidas e também a face obscura do tempo do seu passado, presente e futuro de modo que ele pudesse ler a si mesmo na narrativa de sua própria vida.

A leitura de si nesse conto de Dickens se apresenta como a chave da construção da sua consciência e da transformação de suas ações no presente como abertura para outro futuro. É propriamente a reconciliação com as dimensões do tempo, em torno de feridas e de esquecimentos, num trabalho narrativo e reflexivo que Scrooge é capaz de mudar a si mesmo e ressignificar o mundo. Isso porque seu comportamento diante de si e dos outros, até aquela noite, fizera da sua vivência uma temporalidade fora dos eixos: sua avareza e seu temor permanente de ficar pobre podem ser lidos como uma obsessão pelo futuro, marca da alienação dos tempos modernos. Scrooge renuncia tanto ao passado de suas lembranças de 
infância obscurecidas num esquecimento de fuga quanto ao presente das experiências afetivas e das relações humanas, para viver em prol de uma acumulação desmedida de dinheiro experimentada como expectativa de futuro. Esse traço de Scrooge reflete algo obscuro próprio da nossa época: o encolhimento do nosso espaço de experiência e da nossa memória como consciência e aprendizado (RICOEUR, 1997; KOSELLECK, 2006), assim como uma "hipertrofia de expectativas" compreendida como uma vivência de um presente fugaz e insondável sempre condenado a chegar depois (MARRAMAO, 2008).

No entanto, essa temporalidade vivenciada fora dos eixos ganha novos contornos ao fim do percurso doloroso da autorreflexão de Scrooge. Repensar sua história e seus rumos possíveis faz com que o personagem se torne novamente autor e leitor da sua narrativa de vida, o que lhe possibilita um recomeço. A redenção é refiguração do tempo, uma possibilidade de dar-lhe novos contornos, pois recusa pensá-lo como um movimento de escoamento sempre irreversível e irretocável. Toda essa perspectiva possui no conto de Dickens uma dimensão fortemente moral. Scrooge nota que é preciso aprender com as diversas dimensões da temporalidade; é preciso, de modo constante, recuperar no agora, as dívidas e feridas do ontem e as responsabilidades com o amanhã: "viverei no presente, no passado e no futuro" (DICKENS, 2013, p. 32), afirmaria Scrooge. E completa "a lembrança dos três Espíritos me ajudará a transformar-me, e eu jamais serei surdo às lições que me ensinaram". (DICKENS, 2013, p. 32). Assim, a concepção de tempo, representada nesse conto, faz quebrar a noção da história como destino e fatalidade, pois é sempre possível olhar para frente e para trás, "reparar os erros e mudar a vida" (DICKENS, 2013, p. 33).

De modo bem semelhante, a temática da temporalidade sentida como hipertrofia do horizonte de expectativa e como possibilidade de redenção é o fio condutor do romance "Bleak House" (1949). A história gira em torno do processo judicial, conhecido como o caso "Jarndyce e Jarndyce", que, arrastando-se durante muitos anos, tornou-se um símbolo do Sistema Judiciário inglês no sentido de representar o que ele tinha de mais incoerente, sórdido e atroz. Trata-se da discussão que parece interminável acerca da herança do milionário John Jarndyce em meio 
a diversos testamentos ilegítimos com versões contraditórias sobre o destino daquela fortuna. Após décadas sem resolução definitiva do caso em questão, Richard e Ada são os pretendentes herdeiros da vez. É a partir desse ponto que Dickens se apropria da construção do personagem Richard no que se refere à pretensão de tematizar o problema do tempo e suas implicações na vida humana.

Richard é um garoto repleto de expectativas. Ele nutre um amor incondicional por sua prima, Ada, e vê na resolução da controvérsia judicial a solução de seus maiores problemas. Sua esperança no futuro faz emergir um paradoxo intransponível, pois constitui ao mesmo tempo o traço de sua vivacidade e as condições de sua ruína. À espera de um porvir que nunca chega de um processo que se prolonga demasiadamente no tempo, Richard se desliga dos laços com seu passado e presente: ele se torna prisioneiro dos labirintos soturnos do direito e, por dentro, sofre uma progressiva corrosão que vai decompondo o que há nele de mais nobre e virtuoso. 0 olhar posto no futuro o impede de ver a si mesmo; ele, então, se torna vítima da cegueira de sua própria ambição.

Como resultado, é somente no ato que põe fim à lide judicial, confirmando a legitimidade dos herdeiros, mas anunciando igualmente que a fortuna havia se exaurido em torno dos custos envolvendo o próprio processo, que Richard torna-se novamente capaz de interpretar sua própria narrativa de vida e se arrepende. Ao olhar para trás, torna-se possível aprender com as experiências e assumir os erros, restabelecendo, de modo reconciliado, as relações com o próprio tempo.

Em “Great Expectations”, Pip, um órfão inocente sem nenhuma sofisticação, vivencia igualmente um evento que o lançará numa obsessão pelo futuro. Ao receber uma fortuna de origem desconhecida, ele faz questão de apagar progressivamente os vestígios que o ligam às suas origens e experiências do passado a tal ponto de desprezar Joe, uma figura simples e afável, seu maior companheiro e confidente durante a infância. Pouco a pouco, ele se transforma num sujeito desprezível, superficial e esnobe, conduzido pela sua arrogância, o que o aproxima a cada vez mais da própria imagem de Londres da época, tecida pelo narrador. Assim como nas outras intrigas aqui referenciadas, Pip tem igualmente o tempo 
de rever as escolhas, assumir suas faltas e reconciliar-se com os outros e consigo mesmo.

Embora imersos em intrigas diversas, todos esses personagens traduzem, em maior ou menor medida, as dimensões patológicas da temporalidade humana, especialmente percebidas num excesso de expectativa, numa hipertrofia do olhar em direção ao futuro e no encurtamento do espaço de experiência. Ao mesmo tempo, o rumo de suas histórias inspira a redenção, a retomada do passado das vivências e das narrativas como modo de aprendizado com e no tempo. 0 tempo da memória é o tempo da consciência e da reflexão. É o lugar privilegiado de se fazer outro, de se redimir e de se harmonizar com a própria imagem. Embora as histórias percorram por caminhos de obscuridades e de tropeços, a visão de Dickens é ainda luminosa, pois traduz a capacidade do homem de trapacear o tempo, de mudar-lhe o rumo e de recomeçar. A responsabilidade emerge da memória como oportunidade de revisão do passado e de ação no presente.

Mas parece relevante se ater ainda a essa temática do tempo e da memória de modo a estendê-la às instituições políticas e jurídicas, tomando como ponto de partida, de modo especial, a análise de uma das personagens mais intrigantes da obra de Dickens: Miss Havisham do romance "Great Expectations". Sua referência pode ajudar a repensar, de modo ainda mais completo, as implicações do tempo configurado da memória, junto com suas feridas e traumas, na constituição de nossa existência individual ou coletiva. Mas diferentemente dos outros personagens que foram referenciados até agora, Miss Havisham não é a representação da hipertrofia da espera do futuro. Pelo contrário, sua obsessão patológica é com o passado, dor experimentada como repetição e onipresença. Passa-se, então, a análise da construção da personagem de Miss Havisham por Dickens e suas implicações para a reflexão das feridas da memória num diálogo com Ricoeur (e Freud). 


\section{MISS HAVISHAM, PATOLOGIA E MEMÓRIA: PROPONDO UM DIÁLOGO ENTRE DICKENS, RICOEUR E FREUD}

No romance "Great Expectations", a história de Miss Havisham se cruza com a de Pip, quando este começa a frequentar sua casa para atuar como uma espécie de criado que brinque com sua sobrinha, Estella, e lhe sirva, ao mesmo tempo, como um experimento. Para ela, Pip não seria nada mais que uma isca induzida a apaixonar-se por Estella a fim de educá-la, desde criança, na arte de despedaçar, sem qualquer piedade, os corações dos homens, o que seria, por certo, uma vingança indireta pela dor por ela sofrida. As ações de Miss Havisham são conduzidas pelas feridas de um amor do passado. Ela apaixonara profundamente por um homem a ponto de estabelecer com ele um compromisso matrimonial. " 0 dia do casamento foi marcado, o vestido de noiva foi comprado, a viagem de núpcias foi planejada, as pessoas foram convidadas. 0 dia chegou, mas o noivo não apareceu" (DICKENS, 2013, p. 146). Eram vinte para as nove, quando ela ainda estava vestindo para a cerimônia e recebera uma carta do noivo. Ele a abandonara.

Desde então, todos os relógios da casa ficaram congelados exatamente naquele instante: uma tentativa de estancar o fluxo do tempo e de cristalizar a memória para manter intacto o mesmo ódio e estagnar a própria vida. Determinada por uma memória enferma, Miss Havisham só se nutre do rancor e da vingança, quer parar o movimento do relógio, pois, ao contrário de enfrentar o passado, vive justamente em função dele. Essa presença onipresente e tirana do passado sobre o agora é sentida, no romance, pela descrição que Pip faz dos relógios sobrestados na mesma hora e do próprio ambiente da casa, um lugar insalubre e escuro no qual a vida de Miss Havisham era escondida do sol:

Foi então que comecei a entender que tudo naquele quarto havia parado há muito tempo, como o relógio sobre o toucador e o relógio na parede. Notei que Miss Havisham pôs a joia no lugar exato de onde a havia tirado. Enquanto Estella dava as cartas, olhei de novo para o toucador, e vi que o sapato, outrora branco, hoje amarelo, nunca tinha sido usado. Baixei os olhos para o pé no qual faltava o sapato, e vi que a meia de seda, outrora branca e agora amarela, estava rasgada pelo uso. Sem essa parada de to- 
das as coisas, sem essa imobilidade de todos aqueles objetos desbotados e destruídos, o vestido de noiva frouxo naquele corpo em ruínas não teria me parecido uma mortalha; nem o véu longo se assemelharia tanto a um sudário (DICKENS, 2013, p. 53-54).

A imobilidade do tempo é absorvida pelo ambiente da casa. A luz do dia excluída, o cheiro abafado e expressivo e todas as coisas cobertas de pó e mofo são referências ao velho, ao obsoleto, ao arcaico. Passaramse muitos e muitos anos, e o banquete ainda estava posto sob uma mesa longa, incluído o bolo de noiva, tudo, agora, coberto por insetos de todo tipo. A casa insistia em congelar a imagem da dor como numa fotografia, ainda que destorcida. A pretensão de imobilizar o tempo era experimentada como uma incapacidade de sair da condição de vítima e, portanto, de superar o mal sofrido, de virar a página. Somado ao esforço de manter intacto o ambiente, o desejo de lançar sua sobrinha no plano de vingança ao gênero masculino leva Miss Havisham a destemporalizar a vida, impondo o imperativo incondicional: "Lembre-se! Jamais esqueça!"

Toda essa construção narrativa de Dickens nos conduz propriamente ao enigma da memória e do esquecimento tematizado por Ricoeur (1996; 2007) a partir de sua leitura particular dos escritos de Freud (1914, 1917). Miss Havisham nos faz lembrar que memória e esquecimento são conceitos distintos, mas não opostos, já que seus itinerários se cruzam num lugar que é o da representação do passado. De fato, um enigma parece circundar essa problemática da representação do tempo pretérito, uma vez que "o que foi" já "não é mais", mas deixou marcas, pegadas, vestígios. E isso pode ser reconhecido porque o que foi experimentado pode até não estar presente, como a vivência do abandono por Miss Havisham, mas sobrevive ainda como lembrança. Uma recordação surge, para nós, como uma imagem de uma coisa que está realmente ausente, mas que consideramos como algo que já existiu, no passado. "Encontramse reunidos três traços de forma paradoxal: a presença, a ausência, a anterioridade. Para o dizer de outra forma, a imagem-recordação está presente no espírito como alguma coisa que já não está lá, mas esteve" (RICOEUR, 2003, p. 2). 
É nesse sentido que uma metáfora pode ser apropriada como uma espécie de trabalho de elucidação desse enigma da ausência e da presença no ato de recordação experimentado por Miss Havisham. Trata-se da figura da impressão que fica marcada num bloco de cera. Algumas impressões deixam um rastro mais ou menos expressivo assim como algumas imagens estão mais presentes em nossa memória ou mais suscetíveis ao esquecimento. Quando a impressão é fraca, quase não marca, mas quando é forte demais, poderíamos dizer com Freud, marca demais, danifica a alma, produz trauma (GAGNEBIN, 2011, p. 157). E é em relação a essa carga traumática, originária de uma impressão demasiado forte que fica gravada como memória, que podemos colocar o problema da relação patológica com um passado que insiste em não passar. "Ali ganha toda sua força a dupla aceitação do adjetivo e do substantivo passado: não é somente aquilo que passou, ficou caduco e se extinguiu, mas é, ao mesmo tempo, aquilo que perdura nesse ser findo nas dobras do presente e para todo o futuro" (GAGNEBIN, 2011, p. 160).

E, muitas vezes, o que perdura como passado continua a amarrar o presente em memórias em demasia, cristalizadas em certas representações daquilo que foi: culpas, traumas, feridas, remorsos. Como a representação de todos os relógios da casa de Havisham, o passado se encontra paralisado e onipresente, o que torna a memória mera repetição. A ideia de uma memória impedida, patológica, que remete ao passado não como "o que foi", mas "o que continua sendo" remonta à contribuição da teoria psicanalista tal como pensada por Freud $(1914 ; 1917)$. Diante de uma situação traumática vivenciada no passado, as imagens da memória tendem a se apresentar ao sujeito de duas formas: ou como luto ou como melancolia. 0 luto, de modo geral, é a reação à perda de um objeto de amor ou de alguma abstração que ocupou esse lugar, como a liberdade ou ideal de alguém, e assim por diante (FREUD, 1917, p.1). Por mais que o luto envolva um grave distanciamento daquilo que pode ser considerado normal na vida de alguém, não se pode considerá-lo como uma atitude patológica. "Confiamos que seja superado após certo lapso de tempo, e julgamos inútil ou mesmo prejudicial qualquer interferência em relação a ele" (FREUD, 1917, p.1). 
A melancolia, em sentido oposto, manifesta-se nas pessoas que reagem à perda de forma doentia. Há aqui uma relação difícil com a memória. Como Miss Havisham, a pessoa, lançada na melancolia, não consegue se desligar totalmente do seu objeto de amor que é também seu objeto de ódio. "Combalido pela realidade hostil e catastrófica, o sujeito melancólico interna-se de modo passivo na situação dramática vivida e torna-se incapaz de reagir" (TELES, 2007, p.76). Há, nesse caso, uma diminuição do "sentimento de si" de modo que a pessoa fica inteiramente determinada pelo seu passado, mas o trauma que ela experimentou continua inacessível. Por isso, dizemos que nessa situação a memória torna-se impedida, porque indisponível. Entretanto, isso não significa dizer que ela foi abandonada, o que ocorre é que ela volta mascarada, cheia de sintomas. "0 paciente não recorda coisa alguma do que esqueceu e reprimiu, mas expressa-o pela atuação ou atua-o (acts it out). Ele o reproduz não como lembrança, mas como ação; repete-o, sem, naturalmente, saber que o está repetindo" (FREUD, 1914, grifos do autor). 0 indivíduo, então, submete-se a compulsão de repetição que, agora, passa a substituir o impulso de se recordar a dor e o trauma. Criase uma resistência ao exercício da memória.

Mas o que faz do luto um fenômeno normal, embora doloroso, e da melancolia uma "doença" da memória? Porque diferentemente de repisar as feridas do passado ou tentar apagá-lo a qualquer custo, o luto é um trabalho de rememoração que se revela custosamente, mas também, reciprocamente, libertador (RICOEUR, 2007, p. 86). Se, de um lado, a melancolia é um trabalho que consome o próprio eu, instalando-se como ferida aberta ou queixa insuperável, por outro, o luto indica que o trabalho de rememoração está em marcha ao operar a perda do objeto e implicar uma remodelagem da própria identidade a partir de um processo de interiorização e de desligamento com o passado. Portanto, o que torna o luto um fenômeno normal e até mesmo necessário para a vida humana diante do sofrimento do passado é que "quando o trabalho de luto se conclui, o ego fica outra vez livre e desinibido" (FREUD, 1917, p. 1).

Essa possibilidade que se abre de uma "reconciliação com o material reprimido" (FREUD, 1914) é um exercício permanente, doloroso e vivo de rememoração na busca do desvelamento do passado impedido, no 
reencontro com a verdade "do que foi" e "que não é mais" através de suas pistas e vestígios. Mais uma vez a personagem criada por Dickens pode ser, aqui, requerida. Miss Havisham vivencia o tempo paralisado da memória como "compulsão à repetição": no lugar de lembrar, ela repete o trauma sem saber criticamente que ela o está repetindo. A reprodução do seu ódio, sua vontade de mantê-lo vivo, aceso e destemporalizado, faz dela refém do objeto de ódio que também é o objeto de amor perdido. "Ao repelir a luz do dia, ela tinha se repelido infinitamente mais; [...] ao viver excluída, ela tinha excluído a si mesma" (DICKENS, 2013, p. 315).

Porém, já ao final do romance, ela se arrepende de moldar sua filha na forma de uma vingança para satisfazer seu ressentimento feroz, quando Esthela casa-se com o rival de Pip. Ela, então, se dá conta que incitou o sofrimento de Pip da mesma maneira que um dia um homem havia-lhe provocado. Esse confronto com o passado, a partir de um trabalho de rememoração e de luto, possibilita uma instância crítica, tornando possível o reconhecimento do verdadeiro estado de coisas. Em contato com a ferida do outro, Miss Havisham olha a si diante de sua própria história, reconhece o mal cometido e, desse modo, retira-se do papel de credora de uma dívida eterna e impagável:

Até o momento em que você falou [com Esthela] no outro dia, e até que eu visse em você um espelho que me mostrava o que eu mesma sofri uma vez, eu não sabia o que tinha feito. 0 que eu fiz? O que eu fiz?" E de novo repetiu essas palavras, vinte, cinquenta vezes: "O que eu fiz? (DICKENS, 2013, p. 315)

O momento de redenção de Miss Havisham talvez seja o mais intenso dentre os personagens criados por Dickens, pois aborda o problema do tempo a partir da perspectiva da necessidade de libertação da falta e da dívida, por conversão do próprio sentido do passado. Os acontecimentos do passado ocorreram e são inapagáveis. Não há dúvida que não há como desfazer o que foi feito. "Mas ao invés, o sentido do que nos aconteceu, quer tenhamos sido nós a fazê-lo, quer tenhamos sido nós a sofrê-lo, não está estabelecido de uma vez por todas" (RICOEUR, 1996, p. 4). Não só os acontecimentos permanecem abertos a novas interpretações, como se dá uma reviravolta nos nossos projetos, em função das nossas lembranças, 
por um notável efeito de "acerto de contas" (RICOEUR, 1996, p. 4). 0 que do passado pode então ser mudado é a carga moral, pois é possível ainda buscar nele, sob um olhar intencional do futuro, um outro horizonte possível: o da superação.

\section{CONSIDERAÇõES FINAIS: O USO CRÍTICO DA MEMÓRIA E O TEMPO DA CONSTITUIÇÃO}

Aberta pela obra de Dickens, a percepção da necessidade de um trabalho de memória e de luto que se articula num jogo complexo entre rememoração e de esquecimento ativo remete a várias situações que ultrapassam de longe a cena psicanalítica ou literária. Noções de trauma, de traumatismo e de ferida podem ser transportados para o plano político e intersubjetivo, na medida em que elas se devem a uma estrutura fundamental da existência coletiva (RICOEUR, 2007, p. 92). Conforme Ricoeur, se poderia dizer que certos povos sofrem de demasiada memória, como se sentissem envergonhados pela lembrança das humilhações sofridas num passado remoto e também pelas glórias longínquas; do mesmo modo que outros povos sofrem de falta de memória, como se fugissem perante a obsessão do seu próprio passado (RICOEUR, 1996, p.1). Em ambos os casos, o que é recusado é o uso crítico da própria memória, seja num esquecimento de fuga como estratégia de má-fé ou num repisar eterno de traumas que corre o sério risco de ensejar justamente aquilo que se deveria impedir.

No Brasil, não é diferente: a forma como a transição para a democracia se deu a partir da anistia a todos os lados - igualando torturados e torturadores, vítima e agressor - como um esquecimento imposto, assim como a confirmação desse esquecimento pelo julgamento do STF da ADPF 153 sob o pretexto da necessidade de se prosseguir a vida pública sem olhar para trás ${ }^{1}$ têm caminhado no sentido contrário ao trabalho de luto como uso crítico da memória. Do mesmo modo, discursos negacionistas e revisionistas, sem qualquer base documental, da ditadura militar têm ganhado força como fenômeno nacional a partir da rearticulação de uma ideologia conservadora que tem crescido, pelo 
menos desde as manifestações de junho de 2013, contexto em que já se viam cartazes saudosistas pedindo a volta da ditadura militar (COSTA JUNIOR, 2017). Os discursos e mecanismos sociais e institucionais que pretendem enterrar o passado, sob o argumento de que a história não deve ser vista pelo retrovisor, reforçam a manutenção, entre nós, de um passado que nunca passa e que se alimenta de elementos trágicos, ao mesmo tempo em que se equivoca ao não relembrar para que não se repita (LEMOS, 2019, p.14). Há, com isso, uma resistência ao exercício da memória numa situação em que se recusa qualquer processo de interiorização das violações de direitos no passado e abertura para processos de aprendizado que momentos traumáticos como esse são capazes de engendrar.

É nesse sentido que se pode resgatar de Miss Havisham e da obra de Dickens (como um todo) a importância da reflexão sobre a temporalidade como capacidade de reconstrução de sentidos naquilo que parece intocável ou irreversível e de apropriação do passado como espaço de experiência e de lição, como possibilidade de recomeço. Esse compromisso com a autorreflexão que a narrativa abre implica, em termos políticos, a capacidade de interiorizar os erros e tropeços, de imprimir no tempo a cláusula histórica do "nunca mais" e a reafirmação de princípios normativos que se ligam como promessas ao horizonte normativo de expectativa do presente. Basicamente, é isso que o projeto constituinte de 1988 afirma enquanto processo de disputa de narrativas de variados grupos e de interesses sociais, num ato fundador que confronta o regime militar ao anunciar um processo de transição para democracia que enfrentaria uma longa e contínua fase de efetivação de direitos (LEMOS, 2019, p. 18).

A Constituição de 1988 carrega, pois, o comprometimento público com as dimensões da temporalidade histórica numa tensão entre experiência e expectativa e, com isso, reflete a necessidade de colocar as angústias, as frustrações e as esperanças de outro tempo, o passado, em contato com as nossas, aqui e agora. A vida política, assim como a particular de cada um, se dá, portanto, em mediação constante com o mundo que nos foi legado pelos antepassados (RUSEN, 2011). E o passado, como diria Ricoeur (1996), é um grande cemitério das promessas não 
cumpridas, das potencialidades abafadas, das lutas por direitos que foram massacradas. 0 compromisso constitucional que se inaugura enquanto sentido performativo ${ }^{2}$ do projeto constituinte de reconhecimento intersubjetivo ${ }^{3}$ da igualdade e da liberdade é de resgatar essas potencialidades recalcadas para incorporá-las às nossas expectativas aqui e agora como abertura ao porvir. Dessa perspectiva, é preciso reconhecer o sentimento de endividamento que se tem com a história, assumindo a responsabilidade de seus desvios, faltas e retrocessos.

"Nossa vida no presente dá-se, portanto, em mediação constante com o mundo que nos foi legado, pelos nossos antepassados", diria Rusen (2011, p.283). "É por isso que eles, de certo modo, para nós estão vivos” (RUSEN, 2011, p. 283). Os mortos não estão mortos: eles são parte da vida dos vivos de hoje, pois a comunidade política é herdeira das promessas de democracia, de Estado de direito e de direitos fundamentais não satisfeitas do passado. É essa recepção do passado, num trabalho de compreendê-lo e interioriza-lo que permite um processo de aprendizado social com e na democracia que abre caminho para a autocorreção dos erros e dos tropeços e da reafirmação com a emancipação, especialmente daqueles que foram e são silenciados. Esse processo de elaboração do passado rompe a tirania da memória para dar lugar a um esquecimento ativo e libertador, que não se confunde com estratégias de fuga ou negacionismos. É nesse sentido que a aproximação de Dickens, Ricoeur e Freud ratificam a ideia de que é necessário lembrar para lembrar e para esquecer.

No campo político-jurídico, isso requer uma tradição constitucional narrada e narrável que reconhece que a história das violações ou exclusão de direitos não é nem um peso de um destino inexorável ${ }^{4}$, muito menos um trauma que deve ser esquecido para ser superado. Essa história, ao contrário, deve ser incorporada na nossa consciência histórica como um lugar de experiência e de disputa, espaço de consciência crítica e aprendizado, na medida em que é possível tirar partido dos seus ensinamentos e de assumir a responsabilidade por seus deslizes e desacertos. É dentro dessa lógica que o sentido performativo do projeto constituinte de 1988 não é apenas revigorar os símbolos e sentidos da nossa memória coletiva, renovando-a e alargando-a, mas se 
coloca diante do compromisso de reinventar essas mesmas promessas criadoras, repensando o rumo do presente, pois sabe ouvir as vozes recalcadas do passado. Compreendido assim, esse projeto constitucional encontra-se apto a se enraizar enquanto experiência democrática aberta à possibilidade constante de se autocorrigir no tempo, pois só uma consciência histórica crítica é capaz de fornecer padrões consistentes para que se possa avaliar, reparar e repensar a própria história.

\section{NOTAS}

1 Sobre a crítica à ADPF 153, ver Costa Junior (2009) e Lemos (2019).

2 Sobre o sentido performativo do projeto constituinte e a crítica aos discursos oficiais sobre a transição para a democracia, ver Cattoni de Oliveira (2009).

3 Sobre o problema específico do reconhecimento nas democracias constitucionais, ver: Costa Junior (2019); Fraser (2007) e Honneth $(2003 ; 2007)$

4 Na obra "Constitucionalismo do atraso" (COSTA JUNIOR, 2017), foi discutida criticamente a questão da imagem predominante do Brasil - associada quase sempre de modo pejorativo ao atraso, à passividade e à corrupção - como um discurso compulsivo-repetitivo que reifica a identidade, produto de uma história contada de uma vez por todas.

\section{REFERÊNCIAS}

CATTONI DE OLIVEIRA, Marcelo Andrade. Democracia sem espera e processo de constitucionalização: uma crítica aos discursos oficiais sobre a chamada "transição política brasileira". In: CATTONI DE OLIVEIRA, Marcelo Andrade; MACHADO, Felipe Daniel Amorim (org). Constituição e Processo: a resposta do constitucionalismo à banalização do terror. Belo Horizonte: Del Rey, 2009.

COSTA JUNIOR, Ernane Salles da. Constitucionalismo do atraso. Belo Horizonte: D’Plácido, 2017.

COSTA JUNIOR, Ernane Salles da. A necessidade de reconhecimento e os limites de uma teoria liberal da justiça, Revista Direitos Fundamentais \& Democracia. 2019 , v. 14, n. 2.

COSTA JUNIOR, Ernane Salles da. Constituição, tempo e narrativa: da crise da aceleração das mudanças normativas ao seu enfrentamento. Revista Direitos Fundamentais \& Democracia. 2013, Jun 4; 13(13):81-106. 
COSTA JUNIOR, Ernane Salles da; TAVARES, Fernando Horta; TRUGILHO,Diogo Lima; GOMES, Frederico Fernando Pereira; DE MORAIS, Rane Ferreira Rios Hollanda Cavalcante; PENZIN, Thiago. Responsabilização, Julgamento e Ditadura no Brasil: O Perdão Pode Curar? Revista de Direitos e Garantias Fundamentais, Vitória, n. 6, p. 117-154, 2009.

DICKENS, Charles. Bleak house. London: J. M. Dent, 1949.

DICKENS, Charles. Conto de natal. Santiago: Sociedade Comercial y Editorial Santiago, 1988.

DICKENS, Charles. David Copperfield. 2. ed. São Paulo: Abril Cultural, 1972.

DICKENS, Charles. Grandes esperanças. São Paulo: Landmark, 2013.

DICKENS, Charles. Oliver Twist. Harmondsworth: Penguin Books, 1966.

FRASER, Nancy. Reconhecimento sem ética. Lua Nova, v. 70, n. 1, p. 101-138, 2007.

FREUD, Sigmund. Luto e melacolia. 1917. Disponível em: <http://www.scribd. com/doc/16372739/LUTO-E-MELANCOLIA-FREUD> Acesso em: 20 de Agosto de 2009 .

FREUD, Sigmund. Recordar, repetir e elaborar (novas recomendações sobre a técnica da psicanálise II). 1914. Disponível em: <http://www.scribd.com/ doc/7229887/RECORDARRepetir-e-Elaborar>. Acesso em: 21 de Agosto de 2009 .

GAGNEBIN, Jeanne Marie. Lembrar escrever esquecer. 1. ed. São Paulo: Editora 34 Ltda., 2006.

GAGNEBIN, Jeanne Marie. A memória, a história, o esquecimento. In: DE PAULA, Adna Candido; SPERBER, Suzi Frankl (Orgs.). Teoria Literária e Hermenêutica Ricoeuriana: um diálogo possível. Dourados: Editora UFGD, 2011.

HONNETH, Axel. Luta por reconhecimento: a gramática moral dos conflitos sociais. São Paulo: Editora 34, 2003. 
HONNETH, Axel. Sofrimento de Indeterminação. Uma reatualização da filosofia do direito de Hegel. São Paulo: Editora Singular, Editora Esfera Pública, 2007.

KOSELLECK, Reinhart. Futuro passado: contribuição à semântica dos tempos históricos. Rio de Janeiro: Ed. PUC Rio, Contraponto, 2006.

LEMOS, Tayara Talita. Por constitucionalismo transacional: ditadura, memória, promessa. Belo Horizonte: D’Plácido, 2019

MARRAMAO, Giacomo. Kairós: apología del tiempo oportuno. Barcelona: Gedisa, 2008.

OST, François. 0 tempo do direito. Bauru, SP: EDUSC, 2005

RICOEUR, Paul. A memória, a história, o esquecimento. Tradução: Alain François. Campinas, SP: Editora da UNICAMP, 2007.

RICOEUR, Paul. A memória, a história, o esquecimento. Budapeste, 2003. Disponível em: http://www.uc.pt/fluc/lif/publicacoes/textos_disponiveis_ online/pdf/memoria_historia Acesso em 05 de maio 2013.

RICOEUR, Paul. 0 justo. Trad. Ivone C. Benedetti. São Paulo: Martins Fontes, 2008a-v.

RICOEUR, Paul. O perdão pode curar? 1996. Disponível em: <http://www. lusosofia.net/textos/paul_ricoeur_o_perdao_pode_curar.pdf $>$ Acesso em: $2 \mathrm{de}$ jun. 2009.

RICOEUR, Paul. Tempo e narrativa. Campinas (SP): Papirus, 1997- v. 3

RÜSEN, Jörn. Pode-se melhorar o ontem? Sobre a transformação do passado em História. In: SALOMON, Marlon (Org.). História, Verdade e Tempo, 2011, p. 259-290.

TELES, Edson Luís de Almeida. Brasil e África do Sul: os paradoxos da democracia. Memória Política em democracias com herança autoritária. 2007. 152p. Tese (Doutorado). Universidade de São Paulo. São Paulo. 
Recebido em: 31-08-2019

Aprovado em: 09-12-2019

\section{Ernane Salles da Costa Junior}

Pós-doutor em Direito Constitucional pela Universidade Federal de Minas Gerais (UFMG); doutor em Direito pela mesma instituição e mestre em Teoria do Direito pela Pontifícia Universidade Católica de Minas Gerais (PUC-MG) com a distinção magna cum laude. Realizou estágio doutoral com bolsa sanduíche da CAPES no instituto Fonds Ricoeur, vinculado a École des Hautes Études en Sciences Sociales (EHESS). Professor de Filosofia do Direito e Direito Constitucional. E-mail: profernanesalles@gmail.com.

Universidade Federal de Minas Gerais - UFMG

Av. Pres. Antônio Carlos, 6627 - Pampulha, Belo Horizonte - MG, 31270-901. 